\title{
KRCP's past and future path
}

\author{
Tae-Hyun Yoo \\ Department of Internal Medicine, College of Medicine, Institute of Kidney Disease Research, Yonsei University, Seoul, Republic of Korea
}

\section{Preface}

Kidney Research and Clinical Practice (Kidney Res Clin Pract, KRCP) is the official full-text English journal that represents the Korean Society of Nephrology (KSN), the largest professional society in Korea. KRCP has been published since 1982 and was initially published in Korean as the Korean Journal of Nephrology until 2012. To extend the scope of its readership globally, it was renamed KRCP and became an international, peer-reviewed journal published in English; its subscribers include over 10,000 current members and physicians and scientists from all over the world. KRCP has become an internationally recognized journal listed in SCOPUS, as well as in the emerging sources citation index (ESCI) in 2016. Since January 2012 [1], Professor Gheun-Ho Kim has been the Editorin-Chief of the journal. His dedication to KRCP has been a stepping stone for the advancement and internationalization of Korean kidney disease research. On behalf of KSN members and KRCP Editorial Board Members, we would like to express our gratitude for his passion and hard work, as well as that of the previous editors.

This journal has changed every 5 years, a renovation, with a new Editor-in-Chief and a new team of Deputy

Received August 26, 2020; Accepted August 26, 2020

Correspondence: Tae-Hyun Yoo

Department of Internal Medicine, College of Medicine, Institute of Kidney Disease Research, Yonsei University, 50 Yonsei-ro, Seodaemun-gu, Seoul 03722, Republic of Korea. E-mail:yoosyo316@ yuhs.ac

Copyright (C) 2020 by The Korean Society of Nephrology

(a) This is an open-access article distributed under the terms of the Creative Commons Attribution Non-Commercial License (http://creativecommons. org/licenses/by-nc-nd/4.0/), which permits unrestricted non-commercial use, distribution, and reproduction in any medium, provided the original work is properly cited. and Associate Editors. This issue introduces the future editorial members. I am deeply honored to be selected to be the new Editor-in-Chief of KRCP.

Past

Since conversion to English in 2012, KRCP has published various peer-reviewed academic papers in specialized nephrology fields quarterly both domestically and abroad. As a global kidney journal, numerous international researchers have submitted manuscripts and had them accepted after blinded review by experts and professional editing. KRCP publishes the latest knowledge on scientifically interesting topics related to nephrology. In addition, specialized topics emerging as public health concerns have been reported. In particular, pressing public health issues related to patient care have been presented to readers in a timely manner. For example, during the Middle East respiratory syndrome (MERS) outbreak in 2015, KRCP announced the MERS clinical practice guideline for hemodialysis (HD) facilities with the help of the Korean Society of Nephrology MERS-CoV Task Force Team [2]. Recently, the coronavirus disease 2019 (COVID-19) pandemic has become a public health crisis with over 21.2 million people diagnosed with the virus and 761,000 attributed deaths as of August 16, 2020. HD patients are very difficult to isolate from potential sources of infection due to the nature of dialysis treatment in a limited HD unit. COVID-19 clinical practice guidelines for HD facilities were developed by a joint committee comprised of members from the KSN, the Korean Society for Dialysis Therapy, and the Korea Disease Control and Prevention Agency. Korean clinical practice guidelines for preventing transmission of COVID-19 in HD facilities was also published in KRCP [3]. The current guidelines direct dialysis specialists and dialysis patients 
to recommend prevention, protection, screening, and isolation against the transmission of COVID-19 during this pandemic. Timely publishing of domestic and global health issues in KRCP expands opportunities to share academic knowledge and practical experience that will improve the care of patients both domestically and globally. An issue arising from natural disasters was also published in KRCP. Although the Korean Peninsula has been considered an earthquake-free zone, an earthquake suddenly occurred in the Gyeongju province, which was a major public health issue. In dialysis units, HD treatment was suddenly interrupted due to power failure and the need to evacuate patients for safety reasons. In that special article in a 2019 issue of KRCP, experience of the dialysis unit during a natural disaster in Gyeongju was introduced, and a plan for addressing issues related to natural disasters such as earthquakes was developed [4]. As social issues can also be published in KRCP, recent legislation ("Act on Decisions on Life-Sustaining Treatment for Patients in Hospice and Palliative Care or at the End of Life," act no. 14013) on the suspension of lifesustaining medical care was described, and HD as a lifesustaining treatment at the end of life was discussed [5].

In addition, in cooperation with leading journals, we simultaneously published a section unifying and clarifying the nomenclature for kidney function and diseases to effectively improve global communication $[6,7]$. Moreover, KRCP provided a venue for the shared consensus from joint academic meetings with the Korean Diabetes Association $[8,9]$. Through these processes, we believe that unresolved and undisclosed scientific problems in the field of nephrology, as well as issues across different fields, can be discussed, and through this, the academic level can be raised one step further.

\section{Future}

KRCP's mission during the last 5 years had been to become one of the leading journals worldwide on the topic of nephrology. These could be accomplished, in many ways, to standardize the journal format and publish the valuable manuscript given the interest of many global readers. In order to honor the tradition of KRCP and further expand it in the future, there are several important steps. In order to expand our readership base, we would like to focus on several areas. First, we seek to publish
KRCP bimonthly in the near future, instead of quarterly. In addition, we will streamline the publication process to speed the time of submission and publication as much as possible. At the same time, we will make efforts to invite various reviewers for objective and accurate scientific evaluation. There are amazing new technologies to perform the basic research to nephrology field and remarkable innovation to gather and handle in the numerous clinical data. By introducing state-of-the-art research, KRCP will become one of the best journals in the nephrology field. In addition, we will try to share our knowledge by soliciting many professional reviews from experts in the field.

We are deeply grateful to the previous editors and associate editors who devoted hard work and sacrifice to KRCP's success. First, We wish to thank the previous incumbents of the Editorial Board, Prof. Gheun-Ho Kim as Editor-in-Chief, and Prof. Dae Ryong Cha, Prof. DukHee Kang, Prof. Shin-Wook Kang, Prof. Yon Su Kim, Prof. Cheol Whee Park, Prof. Won Kim, and Prof. Dong-Ryeol Ryu as Associate Editors for their devotion to KRCP. I also would like to thank all previous Editorial Board Members for their hard work. We are pleased to welcome the following new Editorial Board Members: nephrologists Prof. Kyung Don Yoo, Prof. Woo Yeong Park, Prof. So-Young Lee, Prof. Soon Hyo Kwon, Prof. Jong Hyun Jhee, Prof. Jin Joo Cha, and Prof. Seon Ha Baek. KRCP has also invited Prof. Heeyeon Cho to the Editorial Board as a pediatric nephrologist, Prof. Kyung Chul Moon as a kidney pathologist, and Hyunsun Lim, Ph.D. as a statistical editor.

All of the editorial members appreciate the continued interest and advice from our KRCP readers and members of the KSN, and look forward to reviewing your future research submissions. As the KRCP Editorial Committee, we seek to establish KRCP as a journal of the highest caliber in the nephrology field.

Greetings on behalf of the editorial board.

\section{Conflicts of interest}

The author has no conflicts of interest to declare.

\section{References}

[1] Jin DC, Ha IS, Kim NH, et al. Brief report: renal replacement therapy in Korea, 2010. Kidney Res Clin Pract 2012;31: 
62-71.

[2] Park HC, Lee YK, Lee SH, et al.; Korean Society of Nephrology MERS-CoV Task Force Team. Middle East respiratory syndrome clinical practice guideline for hemodialysis facilities. Kidney Res Clin Pract 2017;36:111-116.

[3] Park HC, Kim DH, Yoo KD, et al.; Korean Society of Nephrology COVID-19 Task Force Team. Korean clinical practice guidelines for preventing transmission of coronavirus disease 2019 (COVID-19) in hemodialysis facilities. Kidney Res Clin Pract 2020;39:145-150.

[4] Yoo KD, Kim HJ, Kim Y, et al. Disaster preparedness for earthquakes in hemodialysis units in Gyeongju and Pohang, South Korea. Kidney Res Clin Pract 2019;38:15-24.

[5] Shin SJ, Lee JH. Hemodialysis as a life-sustaining treatment at the end of life. Kidney Res Clin Pract 2018;37:112-118.

[6] Levey AS, Eckardt KU, Dorman NM, et al. Nomenclature for kidney function and disease: executive summary and glossary from a Kidney Disease: Improving Global Outcomes (KDIGO) consensus conference. Kidney Res Clin Pract 2020;39:151-161.
[7] Levey AS, Eckardt KU, Dorman NM, et al. Nomenclature for kidney function and disease: executive summary and glossary from a Kidney Disease: Improving Global Outcomes (KDIGO) consensus conference. Kidney Int Rep 2020;5: 965-972.

[8] Hur KY, Kim MK, Ko SH, Han M, Lee DW, Kwon HS; Committee of Clinical Practice Guidelines; Korean Diabetes Association and Committee of the Cooperative Studies; Korean Society of Nephrology. Metformin treatment for patients with diabetes and chronic kidney disease: a Korean Diabetes Association and Korean Society of Nephrology consensus statement. Kidney Res Clin Pract 2020;39:32-39.

[9] Hur KY, Kim MK, Ko SH, Han M, Lee DW, Kwon HS; Committee of Clinical Practice Guidelines, Korean Diabetes Association; Committee of the Cooperative Studies, Korean Society of Nephrology. Metformin treatment for patients with diabetes and chronic kidney disease: a Korean Diabetes Association and Korean Society of Nephrology consensus statement. Diabetes Metab J2020;44:3-10. 